Investigaciones Fenomenológicas, n. 8, 2011, 77-88.

e-ISSN: $1885-1088$

\title{
LA INTENCIONALIDAD: ENTRE HUSSERL Y LA FILOSOFÍA DE LA MENTE CONTEMPORÁNEA*
}

\author{
Marta Jorba Grau \\ Universitat de Barcelona, España \\ martajorba@ub.edu
}

\begin{abstract}
Resumen: Las discusiones sobre la intencionalidad en la Filosofía de la mente contemporánea se plantean en un marco un tanto ajeno al de la Fenomenología, bajo la suposición, de modo bastante generalizado, de que hay una separación entre intencionalidad y consciencia (fenoménica). Mi objetivo en este artículo es, en primer lugar, exponer tal supuesto. En segundo lugar, presentar los elementos clave de la teoría de la intencionalidad en las Investigaciones Lógicas de Husserl para presentar una visión que se opone a tal separación. $Y$, en tercer lugar, finalizar con un tema común a ambos espacios de discusión, el de una experiencia o vivencia propia del pensamiento, que surge como un problema para muchas visiones analíticas contemporáneas y que tiene una explicación que puede derivarse de la concepción de Husserl.
\end{abstract}

Palabras clave: Intencionalidad, consciencia fenoménica, experiencia del pensamiento, Husserl.

\begin{abstract}
In contemporary Philosophy of mind, discussions about intentionality are set up in a quite different framework from the phenomenological one, assuming, in general, a separation between intentionality and (phenomenal) consciousness. My aim in this paper is, firstly, to present this assumption. Secondly, I will put forward the key elements of Husserl's theory of intentionality in the Logical Investigations in order to present a view which is opposed to this assumption. And thirdly, I will end up with a common topic for both frameworks, that is, the topic of a specific experience of thinking, which emerges as a problem for many contemporary analytic views and which has an explanation that can be derived from Husserl's conception.
\end{abstract}

Keywords: Intentionality, phenomenal consciousness, experience of thinking, Husserl.

\section{LA INTENCIONALIDAD EN LA FILOSOFÍA DE LA MENTE CONTEMPORÁNEA}

En general, la intencionalidad es entendida como el "sobre qué" (aboutness) de la experiencia y el pensamiento, el rasgo de la mente que nos relaciona con el mundo, en una relación que consiste en el hecho de que ciertos estados mentales tienen contenido, tienen un "sobre qué". Hay diferentes teorías sobre

* La investigación para este trabajo fue financiada por el programa FPU del Ministerio de Educación y Ciencia y por Dirección General de Investigación del Gobierno de España, proyecto de investigación HUM2006-08236. 
cómo debemos entender esta relación, pero para tener un mapa de la situación, así como para delimitar el punto de partida de este artículo, podemos distinguir tres aproximaciones en la filosofía analítica y las ciencias cognitivas. En primer lugar, la aproximación de la filosofía del lenguaje: intenta clarificar la intencionalidad de la consciencia a través del análisis de las propiedades lógicas de oraciones usadas para describir fenómenos psíquicos. En oraciones que involucran verbos psicológicos como pensar, creer, etc., los principios ordinarios de sustitutividad correferencial y de generalización existencial fallan (características de los Ilamados contextos intensionales). Gottlob Frege, Bertrand Russell o Saul Kripke son figuras principales de este tipo de aproximación. Se puede pensar que las paradojas de la intencionalidad se hallan en un campo intermedio entre la filosofía del lenguaje y la filosofía de la mente. En segundo lugar, la aproximación de la naturalización de la intencionalidad: intenta explicar cómo se puede naturalizar la intencionalidad, es decir, cómo puede ser explicada a través de mecanismos no intencionales. La intuición que subyace a este tipo de teorías es que "intencionalidad" es más bien un concepto oscuro que ha confundido a muchos filósofos a la hora de pensar sobre la mente y sus propiedades. Puede ser descrito como un proyecto con diferentes maneras de abordar el objetivo de la naturalización, esto es, de tratar de explicar el "sobre qué" de la experiencia para las ciencias naturales o empíricas. Es el tipo de aproximación defendido por W. O. Quine, Daniel Dennett, Jerry Fodor, Fred Dretske, Ruth Millikan y otros. En tercer lugar, encontramos una aproximación que enfatiza la necesidad de incluir la perspectiva de la primera persona en la investigación sobre la experiencia argumentando que una descripción detallada de la consciencia es una parte esencial de la investigación filosófica sobre la intencionalidad. Algunos de los pensadores que están en esta línea son John Searle, Galen Strawson, Charles Siewert o Gianfranco Soldati. Esta última aproximación es la que más afinidad tiene con el planteamiento fenomenológico en general.

Excepto para algunos autores del tercer tipo de aproximación, el escenario de la filosofía analítica de la mente parece asumir una separación entre intencionalidad y consciencia ${ }^{1}$. La filosofía de la mente post-conductista y las ciencias cognitivas han procedido bajo el supuesto de que la intencionalidad y la

\footnotetext{
${ }^{1}$ Para una visión general, véase Terence Horgan / John Tienson, "The Intentionality of Phenomenology and the Phenomenology of Intentionality", en David Chalmers (ed.), Philosophy of Mind: Classical and Contemporary Readings, Oxford, Oxford University Press, 2002.
} 
consciencia -entendida como consciencia fenoménica o como el "como qué es" ("what it is like") tener una experiencia² - han de ser tratadas separadamente. Así, los estados mentales con carácter fenoménico no son intencionales (los ejemplos son generalmente estados sensoriales como el dolor, el picor, etc.). Y estados típicamente intencionales, como creencias, deseos, pensamientos, etc., son estados en los cuales no tenemos consciencia fenoménica. Es importante notar que, de acuerdo con esta visión, aunque pueda haber estados complejos que sean a la vez intencionales y fenoménicos (como los perceptivos), sus caracteres fenoménicos e intencionales son separables. La razón puede ser que es más fácil tratar con la experiencia consciente si intentamos entender el reino mental a través de la siguiente distinción. Por una parte, como lo caracteriza David Chalmers (1995), tenemos los "problemas fáciles" de la consciencia, que tratan básicamente de cómo la mente puede procesar información, reaccionar a estímulos medioambientales o exhibir capacidades de discriminación, categorización o introspección. Aunque todas ellas puedan ser propiedades admirables, son metafísicamente comprensibles porque se pueden tratar con la maquinaria estándar de las ciencias cognitivas y se pueden explicar en términos computacionales o neuronales. Así, en principio puede darse una naturalización de estos aspectos de la consciencia, y el fisicalismo o algún tipo de materialismo está garantizado. De acuerdo con esta caracterización, la intencionalidad es parte de los problemas fáciles porque es simplemente la característica de la mente que nos permite tener información sobre el mundo. Por otra parte, el "problema difícil" de la conciencia -o simplemente el problema de la consciencia- consiste en explicar el carácter fenoménico o cualitativo de las experiencias conscientes. La consciencia fenoménica es, en palabras de Ned Block, "experiencia. Las propiedades F-conscientes son propiedades experienciales. Los estados Fconscientes son estados experienciales, esto es, un estado es F-consciente si tiene propiedades experienciales. La totalidad de las propiedades experienciales de un estado es el "como qué es" tenerlo"3. Este rasgo es algo subjetivo que supone un problema para el fisicalismo o el naturalismo en general.

\footnotetext{
${ }^{2}$ Véase Thomas Nagel, "What Is It Like to Be a Bat", Philosophical Review 83 (1974) 435-450; John Searle, The Rediscovery of the Mind, Cambridge, MA, MIT Press, 1992.

3 "P-consciousness [phenomenal consciousness] is experience. P-conscious properties are experiential properties. P-conscious states are experiential states, that is, a state is P-conscious if it has experiential properties. The totality of experiential properties of a state is "what it is like" to have it" (Ned Block, Consciousness, Function, and Representation. Collected Papers, Volume 1, Cambridge, Mass., MIT Press, 2007, p. 166). La traducción es nuestra.
} 
La estrategia de separación puede tomar diferentes formas: podemos llamar "separatismo metafísico" a la tesis que afirma que la división entre dos aspectos metafísicamente diferentes de la conciencia o podemos tener un "separatismo pragmático", que viene a ser una estrategia de investigación que puede ser adoptada independientemente de la posición que uno tome con respecto al separatismo metafísico ${ }^{4}$. La estrategia del separatismo pragmático contiene en sí misma dos apuestas diferentes. La primera asume que la división da la base para los avances conceptuales y empíricos en lo que sabemos sobre la mente, y esto se ha hecho de la mano de las teorías computacionales clásicas, la investigación en inteligencia artificial, etc., que han modelado la intencionalidad independientemente de la consciencia. La segunda apuesta sostiene que si tratamos la intencionalidad como un fenómeno unificado tanto para el reino mental como para el no mental (incluyendo aquellos fenómenos no mentales para los cuales seguro que no hay consciencia), esto resultará tener los mismos beneficios; ésta es la apuesta de las aproximaciones informacionales y teleológicas a la intencionalidad (de Fred Dretske y Ruth Millikan, entre otros, respectivamente -incluída en el segundo tipo de aproximación en nuestra presentación inicial del panorama de la filosofía analítica actual).

Una vez se ha establecido la división como supuesto para las discusiones sobre el tema, los autores toman diferentes posiciones. Uno de los movimientos más comunes es una reducción del aspecto fenoménico al intencional. Los llamados representacionistas de primer orden (como Fred Dretske o Michael Tye) argumentan que para descubrir el "como qué es" estar en cierta experiencia, hay que mirar a lo que está intencionalmente representado, lo que significa que las experiencias no tienen propiedades intrínsecas o no-intencionales por sí mismas. Los detractores de esta visión, como Ned Block, argumentan que el contenido fenoménico puede no ser representacional en absoluto ${ }^{5}$.

Más allá de las respectivas teorías concretas sobre la intencionalidad, el punto que queríamos poner de relieve es el supuesto de separación que subyace a la mayor parte de las discusiones analíticas contemporáneas.

\footnotetext{
${ }^{4}$ Véase Robert A. Wilson, "Intentionality and Phenomenology", Pacific Philosophical Quarterly 84 (2003) 413-431.

${ }^{5}$ Véase Ned Block, op. cit., p. 177.
} 


\section{LA INTENCIONALIDAD EN LAS INVESTIGACIONES LÓGICAS DE HUSSERL}

Investigaciones lógicas fue la obra fundacional para la fenomenología como movimiento filosófico y ha sido objeto de estudio de muchos filósofos y filósofas desde entonces. Probablemente, la innovación más importante que Husserl presenta en esta obra con respecto a la teoría de la intencionalidad es una descripción de ésta que distingue entre el objeto y el contenido del acto mental: el objeto intencional no es parte del acto. Hablamos de innovación respecto de Brentano $^{6}$, que consideraba el objeto intencional como inmanente al acto mental. Esto crea un reto al que responde la quinta de las Investigaciones lógicas: mostrar cómo los elementos presentes en un acto mental hacen posible que el acto se refiera a algo o signifique algo que, por su naturaleza, no es parte del acto $^{7}$.

Un aspecto que debemos considerar antes de presentar los elementos básicos de la teoría de la intencionalidad es su carácter completamente general y formal. Trata de dar una solución al problema de cómo en general algo, en virtud de su constitución interna (partes y momentos) puede lograr referirse a otra cosa que no es idéntica con ella ni parte de ella. Esta formalidad evita cualquier asunción que uno pueda hacer sobre la naturaleza del objeto intencional. Aunque Husserl no da una especificación inicial de qué tipo de cosas son los objetos intencionales, la situación es diferente con respecto al tipo de cosa que puede tener objetos intencionales. Cuando hay intencionalidad, encontramos vivencias intencionales (intentionale Erlebnisse) o actos, como veremos a continuación.

Husserl apela a los psicólogos modernos (por ejemplo, a Wundt) para introducir el término "vivencia":

En este sentido, vivencias o contenidos de consciencia son percepciones, representaciones de la fantasía y de imagen, los actos del pensar conceptual, suposiciones y dudas, alegrías y penas, esperanzas y miedos, deseos y voliciones, etc., tal como tienen lugar en nuestra consciencia. ${ }^{8}$ 1924.

${ }^{6}$ Véase Franz Brentano, Psychologie vom empirischen Standpunkt, Leipzig, Ducker and Humblot,

7 Véase David Bell, Husserl, London, Routledge, 1990, p. 115.

8 "In diesem Sinne sind die Wahrnehmungen, Phantasie- und Bildvorstellung, die Akte des begrifflichen Denkens, die Vermutungen und Zweifel, die Freuden und Schmerzen, die Hoffnungen und Befürchtungen, die Wunsche und Wollungen u. dgl., so wie sie in unserem Bewußtsein vonstatten gehen, Erlebnisse oder Bewußtseinsinhalte". Edmund Husserl, Logische Untersuchungen. Zweiter Teil. Unter- 
Dentro de los eventos de la consciencia, Husserl distingue la categoría de los actos (Akte) como "vivencias intencionales" de las vivencias no intencionales. La diferencia específica es, afirma Husserl,

evidente en múltiples casos. En la percepción algo es percibido, en la representación en imágenes algo es representado en imágenes, en las expresiones lingüísticas algo es expresado, en el amor algo es amado, en el odio algo es odiado, en el deseo algo es deseado, etc. ${ }^{9}$

Este "algo" nos da una pista para saber si una experiencia es intencional o no.

Deberíamos añadir que el hecho de que en algunas vivencias se miente algo no significa nada más que la presencia de ciertas vivencias que tienen el carácter de intención, específicamente, de intención representativa, judicativa, etc. Con la excepción de algunos casos especiales, no hay dos cosas presentes en la vivencia -el objeto vivido junto con la vivencia misma dirigido a él- ni encontramos dos cosas relacionadas en el modo de una parte y un todo. Sólo hay una cosa presente, dice Husserl, la vivencia intencional ${ }^{10}$.

No todas las vivencias se dirigen a algo del mismo modo. Husserl distingue tres modos de variación. Siendo la misma la objetualidad ${ }^{11}$, los actos pueden variar con respecto a lo que Husserl Ilama "cualidad" (Qualität)". Con respecto a un estado de cosas $e$, es posible, entre otras cosas: a) juzgar que $e, b)$ preguntarse si $e, c)$ esperar que $e, d$ ) pensar el pensamiento de que $e$. Los actos de estos ejemplos son actitudes proposicionales, pero la distinción de cualidad es válida también para actos dirigidos a individuos o personas, por ejemplo, en actos nominales (recordar a $x$, pensar en $x$ ).

Si la objetualidad permanece la misma y la cualidad también, hay una segunda dimensión de variación, a saber, la "materia" (Materie) o el aspecto bajo el cual el acto presenta su objeto. Si tomamos el siguiente ejemplo: a) pienso en el vencedor de Jena y b) pienso en el vencido de Waterloo; podemos ver que estas representaciones tienen la misma cualidad y refieren al mismo obje-

suchungen zur Phänomenologie und Theorie der Erkenntnis, Hua XIX, The Hague, Martinus Nijhoff, 1984, V $\S 2$.

9 "Es drängt sich an beliebigen Beispielen unverkennbar entgegen. In der Wahrnehmung wird etwas wahrgenommen, in der Bildvorstellung etwas bildlich vorgestellt, in der Aussage etwas ausgesagt, in der Liebe etwas geliebt, im Hasse etwas gehaßt, im Begehren etwas begehrt usw". Ibidem, V, § 10.

10 Véase ibidem, V, §11.

11 Traduce "Gegenständlichkeit", que se refiere al objeto en el modo en que la vivencia se dirige a él. Usamos esta traducción para distinguirlo de "objetividad" (Objektivität). 
to, pero la dimensión del acto que presenta el objeto varia. La materia presenta el objeto en un cierto modo: "La materia (...) es aquella propiedad del acto incluída en el contenido fenomenológico del mismo, que no sólo determina la aprehensión del objeto por el acto sino que también determina como qué lo aprehende, qué notas, relaciones, formas categoriales el acto atribuye al objeto $^{\prime 12}$. Es importante notar que la misma materia no puede referir a dos objetos distintos, pero materias diferentes pueden tener el mismo objeto como referencia, como muestra el ejemplo. La materia es el elemento en el acto que precisamente da la referencia a este objeto y no a otro ${ }^{13}$. Cómo se lleva a cabo este referir por parte de la materia es algo que Husserl deja sin $\operatorname{explicar}^{14}$ y es probablemente una debilidad de su teoría. Si en la dimensión de la cualidad encontrábamos actos tanto proposicionales como nominales, lo mismo vale para la dimensión de la materia.

Al todo que forman cualidad y materia lo llama Husserl "esencia intencional" (intentionales Wesen), y concibe a ambos como dos momentos (partes dependientes) inseparables. Cuando los actos son tales que tienen la función de dar significado, entonces habla de "esencia de significado" (bedeutungsmäßiges Wesen). Una vez vista esta distinción, nos podemos preguntar qué estatuto ontológico tienen estos elementos. La respuesta de Husserl es que son especies -o tipos-, esto es, lo que las diferentes cualidades y materias particulares tienen en común, respectivamente. Las especies se ejemplifican en los casos particulares. Esto vale también para la esencia intencional. El estatuto ontológico que Husserl atribuye a los actos como especies - de los que los actos particulares son instancias o ejemplificaciones - le permite evitar la tesis psicologista que considera los actos y sus contenidos como meramente psicológicos ${ }^{15}$.

\footnotetext{
12 "Die Materie [...] ist die im phänomenologischen Inhalt des Aktes liegende Eigenheit desselben, die es nicht nur bestimmt, dass der Akt die Jeweilige Gegenständlichkeit auffasst, sonder auch als was er sie auffasst, welche Merkmale, Beziehungen, kategorialen Formen er in sich selbst ihr zumisst". Edmund Husserl, Logische Untersuchungen, $\mathrm{V}, \S 20$.

${ }^{13}$ Véase Ibidem, $\mathrm{V}, \S 21$.

${ }^{14}$ Véase David Bell, op. cit., p. 120

${ }^{15}$ Hay todavía otra tercera posible variación con respecto a las vivencias intencionales, que presentamos en nota porque es secundaria para el tema que nos ocupa. La esencia intencional del acto no agota su descripción fenomenológica, lo que significa que dos actos pueden tener la misma cualidad y materia pero ser descriptivamente diferentes. Si nos movemos hacia una fuente que produce un sonido de agua -cuya intensidad se mantiene por un rato-y luego nos alejamos de ella, algo varia en nuestra vivencia: es diferente oír el sonido del agua cerca o lejos de la fuente. Husserl llama al elemento que varia "contenido presentativo" (darstellender Inhalt), y en el caso de la percepción externa, se trata de sensaciones (Empfindungen). Las sensaciones, para Husserl, no son intencionales. El dolor, el mareo, el picor, etc., son vivencias pero no son intencionales, no se refieren a un objeto. Esta constatación separa a Husserl de teorías representacionistas o intencionalistas fuertes que defienden que toda vivencia o experiencia es intencional (tesis defendida por Brentano y recientemente por Tim Crane, entre otros).
} 
Hemos presentado el marco general de las teorías de la intencionalidad, tanto de la filosofía analítica contemporánea como de las Investigaciones lógicas de Husserl. Ahora queremos destacar una cuestión que nos parece relevante. De la presentación de las Investigaciones lógicas se desprende claramente que Husserl considera la intencionalidad como vivida o experienciada, y esto nos permite decir que el tema de los fenomenólogos clásicos (sólo hemos visto el caso de Husserl pero vale también para otros fenomenológos) es la intencionalidad en tanto que consciente (fenoménica). Esto ya marca una oposición a la tesis de la separación que hemos presentado anteriormente.

\section{UN TEMA COMÚN: EL CARÁCTER FENOMÉNICO DEL PENSAMIENTO}

La consecuencia que nos interesa poner de relieve es que la descripción de Husserl toma posición respecto a un tema controvertido y discutido actualmente sobre el carácter fenoménico de los estados cognitivos: en el seno de la discusión en filosofía de la mente, está aceptado (aunque también hay cierta oposición) que hay un "como qué es" ("what it is like") tener una percepción, o sentir dolor, picor, etc., pero es controvertida la cuestión del carácter fenoménico de estados que no son sensoriales, esto es, de estados mentales de pensamiento, comprensión, o lo que podemos denominar "cognitivos" en general.

Pensemos en Liv Ullman. Ahora consideremos: ¿hay algo "como qué es" tener este pensamiento? ¿Quizá formáis una imagen visual de ella, o sentís las palabras "Liv Ullman" en una expresión interna? Nada de esto parece apuntar al carácter fenoménico de lo que es pensar en Liv Ullman: uno puede tener la imagen visual mientras está pensado en otra persona de aspecto similar (la hermana gemela de la actriz, si la tuviera), o puede ser el caso que tengamos la expresión interna mientras pensamos en otra persona Ilamada Liv Ullman. La intuición de que el pensamiento como tal tiene cierta fenomenalidad que no es la del carácter de los estados perceptivos asociados es la base para aquellos que piensan que hay una experiencia o vivencia especifica o propia del pensamiento. Un ejemplo parecido lo encontramos en las Investigaciones lógicas de Husserl ${ }^{16}$ : alguien escucha atentamente un complejo de sonidos totalmente

\footnotetext{
${ }^{16}$ Véase, Edmund Husserl, Logische Untersuchungen, V, § 14.
} 
nuevo para él, de tal forma que es meramente un complejo acústico y más tarde, cuando está familiarizado con su significado (ha aprendido la lengua en cuestión, por ejemplo), escucha la cadena de sonidos en una conversación y la entiende. El ejemplo de la comprensión es aducido y discutido también por diferentes filósofos contemporáneos ${ }^{17}$. Después del ejemplo, Husserl se pregunta: ¿cuál es la diferencia en ambos casos (no entender y entender)? ¿Dónde radica este plus de la expresión entendida por encima de los sonidos articulados vacíos de significado? Su respuesta es que radica en el "carácter" de la vivencia intencional, que es otro nombre para la cualidad y la materia. Por de pronto, consideremos la intencionalidad como vivida o experienciada implica que tanto la cualidad como la materia, partes dependientes del acto, son dos elementos vividos también. Así, que la cualidad sea una característica vivida, experienciada, significa que hay diferencias experienciales entre las diferentes cualidades: si un cierto estado intencional es una imaginación, una representación, una percepción, un juicio, es reconocido a nivel de su instanciación por su diferente manera de ser experienciado.

"Carácter" también refiere, según Husserl, a la materia, de modo que la diferencia entre entender y no entender no radica sólo en la cualidad sino que la materia también es distinta. Como la cualidad, la materia es vivida, lo que significa que el modo como el objeto nos es dado (el objeto con ciertas características) es vivido, experienciado, es decir, que el significado es experienciado (porque es en la materia donde el significado como especie se ejemplifica, de acuerdo con la teoría husserliana de especies y ejemplificaciones en las Investigaciones lógicas). De este modo, el significado del acto pertenece al contenido experienciado. Si asociamos lo experienciado y el carácter cualitativo, y tenemos un contenido experienciado de carácter conceptual, tendremos los correspondientes "qualia conceptuales"18.

La objeción más común a la que recurren los filósofos contemporáneos que se oponen a reconocer una experiencia o vivencia específica del pensar es la de

\footnotetext{
17 Véase Galen Strawson, Mental Reality, Cambridge, MA, MIT Press, 1994; Charles Siewert, The Significance of Consciousness, New Jersey, Princeton University Press, 1998; Gianfranco Soldati, "Begriffliche Qualia. Zur Phänomenologie der Bedeutung", en Thomas Grundmann et al. (eds.), Anatomie der Subjektivität: Bewusstsein, Selbstbewusstsein und Selbstgefühl, Frankfurt, Suhrkamp, 2005; Fabian Dorsch / Gianfranco Soldati, "Conceptual qualia and communication", en Interaction Design Institute Ivrea (ed.), The Foundations of Interaction Design, 2004 [internet].

18 Véase Fabian Dorsch / Gianfranco Soldati, op. cit. Aquí "qualia" y "cualidad" deben ser distinguidos. "Cualidad" es el término técnico de Husserl, mientras que "qualia" hace referencia al aspecto cualitativo, fenoménico o experiencial.
} 
los aspectos sensoriales del pensamiento. La idea es que las vivencias o estados de pensamiento, cognitivos, como la comprensión, tienen carácter fenoménico o son conscientes sólo en la medida en que se manifiestan a través de percepciones, sensaciones, etc. Si aceptamos que hay una experiencia o vivencia del pensamiento, su carácter consciente, fenoménico, etc., vendrá por los estados sensoriales que van asociados al pensamiento. Así, Carruthers afirma:

[...] Los pensamientos no son fenoménicamente conscientes per se. Nuestros pensamientos no son como nada, en el sentido relevante, excepto en la medida en que pueden ser asociados con imágenes visuales u otras imágenes o sentimientos emocionales, que serán fenoménicamente conscientes en virtud de su estatus cuasi-sensorial. [En la expresión interna] la consciencia fenoménica se adjuntará a los sonidos hechos imagen de las oraciones, no a los contenidos de estas oraciones, esto es, no a los pensamientos que de este modo son considerados. ${ }^{19}$

Una réplica común entre los filósofos que defienden una vivencia o experiencia específica del pensamiento es contestar que los estados (o experiencias) en cuestión pueden tener lugar, y de hecho este es el caso, sin la presencia simultánea de representaciones sensoriales, símbolos o signos. Cuando uno oye "pintarán la Torre Eiffel", normalmente se forma una imagen visual de la Torre Eiffel siendo pintada. Pero otras personas puede que no lo hagan, y una representación tal en imágenes no es algo necesario ni es parte de la experiencia de entender o pensar. Charles Siewert ${ }^{20}$ ha aportado otros ejemplos de pensamientos que son demasiado complejos o que desaparecen de forma inmediata para mostrar que sería imposible representarlos sensorialmente. Otro tipo de réplica consiste en decir que algunos pensamientos pueden tener las mismas imágenes asociadas pero diferente carácter fenoménico, y al revés, podemos asociar diferentes imágenes a dos proferencias de una misma oración separadas en el tiempo y que tengan el mismo carácter fenoménico. Un ejemplo más para esta variación es el caso de los homónimos: el carácter fenoménico, el cómo qué es para uno pensar en un banco (de una plaza) es diferente de lo que es para uno pensar en un banco (de dinero), aunque ambos conceptos se escriben y pronuncian igual.

19 " $[. .$.$] Thoughts aren't phenomenally conscious per se. Our thoughts aren't like anything, in the$ relevant sense, except to the extent that they might be associated with visual or other images or emotional feelings, which will be phenomenally conscious by virtue of their quasi-sensory status. [In inner speech] phenomenal consciousness will attach to the imaged sounds of the sentences, not to the contents of those sentences, i.e. not to the thoughts that are thereby entertained". Peter Carruthers, "Conscious Experience versus Conscious Thought", en Uriah Kriegel / Kenneth Williford (eds.), Consciousness and Self-Reference, Cambridge, Mass., MIT Press, 2006, pp. 6s.

${ }^{20}$ Véase Charles Siewert, op. cit. 
Los filósofos contemporáneos que defienden una vivencia propia del pensar parecen no acudir inmediatamente a la teoría fenomenológica de la intencionalidad. Optan pues por, o bien poner sobre la mesa casos particulares e indicar cómo en éstos se puede ver una experiencia tal, o bien acuden a otro tipo de argumentos de carácter general, basados por ejemplo en el conocimiento introspectivo ${ }^{21}$ o distintivo de primera persona ${ }^{22}$, que no hemos tratado aquí. Pero el caso es que, debido al marco de separación que se asume en la filosofía de la mente contemporánea, estos autores tienen que argumentar a favor de una tesis que para la fenomenología parece ser uno de los puntos de arranque. Para Husserl, no es una tesis a defender sino un punto central de partida para su teoría de la intencionalidad, algo así como una noción primitiva (vivencia intencional) que sustenta toda la teoría. Quizá esto es así debido al carácter descriptivo de la aproximación fenomenológica a la intencionalidad, que apunta a mostrar qué es lo que encontramos cuando miramos reflexivamente nuestra vida mental, sin pronunciarse acerca de la posible reducción de la intencionalidad a un fenómeno más básico.

Pese a la rareza de la situación vista desde un "lado" u otro (por no decir una "tradición" u otra), hemos intentado mostrar que hay temas comunes (como éste) y que el debate entre ambos lados es interesante y fértil.

\section{OTRAS REFERENCIAS BIBLIOGRÁFICAS}

J. Chalmers, David, "Facing up to the Problem of Consciousness", Journal of Consciousness Studies 2/3, 1995, 200-219.

Gallagher, Shaun / Zahavi, Dam, The Phenomenological Mind, London, Routledge, 2008.

KüNNE, Wolfgang, "Edmund Husserl: Intentionalität", en: Joseph Speck (ed.), Grundprobleme der großen Philosophen: Philosophie der Neuzeit, Bd. 4, Göttingen, Vandenhoeck \& Ruprecht, 1986.

SMITH, Barry / SMITH, David W., The Cambridge Companion to Husserl, Cambridge, Cambridge University Press, 1995.

\footnotetext{
${ }^{21}$ Véase David Pitt, "The Phenomenology of Cognition or What is it Like to Think That P?", Philosophy and Phenomenological Research, vol. LXIX, 1 (2004).

${ }^{22}$ Véase Charles Siewert, op. cit.
} 
Welton, Donn, (ed.), The New Husserl. A Critical Reader, Indiana, University Press, 2004.

ZAHAVI, Dam, "Intentionality and Experience", Synthesis Philosophica, vol. 40, 2 (2005) 299-318. 